\title{
Otomastoidite por Lagochilascaris Minor em Criança: Relato de Caso
}

\section{Minor Lagochilascaris Otomastoiditis in a Child: Case Report}

\author{
Valeriana de Castro Guimaraes*, Alverne Passos Barbosa**, Leandro Azevedo de Camargo***, \\ Paulo Humberto Siqueira ****, Jaime Custódio da Silva Filbo*****, Victor Labres da Silva Castro******, \\ Maria Alves Barbosa $* * * * * *$, Dulcinéa Maria Barbosa Campos $* * * * * * *$.
}

* Doutoranda. Responsável pelo Serviço de Audiologia da Clínica de Otorrinolaringologia HC/UFG.

*** Doutor em Biologia Molecular. Professor Adjunto de Parasitologia do Instituto de Patologia Tropical e Saúde Pública - UFG.

*** Mestre em Otorrinolaringologia. Professor Substituto da Clínica de Otorrinolaringologista da Faculdade de Medicina - UFG

***** Especialista em Otorrinolaringologia. Professor Assistente da Clínica de Otorrinolaringologista da Faculdade de Medicina - UFG

******* Médico. Mestrando em Medicina Tropical da Área de Concentração em Parasitologia. Instituto de Patologia Tropical e Saúde Pública - UFG

******** Médico Residente em Otorrinolaringologia do Hospital das Clínicas - UFG.

********* Doutora em Enfermagem. Professora Titular da Faculdade de Enfermagem - UFG.

********* Doutora em Parasitologia. Professora Titular do Instituto de Patologia Tropical e Saúde Pública - UFG.

Instituição: Hospital das Clínicas (HC) e Instituto de Patologia Tropical e Saúde Pública (IPTSP) da Universidade Federal de Goiás (UFG) Goiânia / GO - Brasil.

Endereço para correspondência: Valeriana de Castro Guimarães - Hospital das Clínicas da Universidade Federal do Goiás - Primeira Avenida, s/n - Setor Leste Universitário - Goiânia / GO - Brasil - CEP: 74605-020 - E-mail: valeriana.guimaraes@gmail.com

Artigo recebido em 2 de Maio de 2009. Artigo aprovado em 21 de Junho de 2009

\section{RESUMO}

Introdução:

Objetivo:

Relato do Caso:

Comentários Finais:

Palaviras-chave:

SUMMARY

Introduction:

Objective:

Case Report:

Final Comments:

Keywords:
A lagochilascariose é uma a zoonose emergente determinada pela presença do helminto Lagochilascaris minor em tecidos humanos. A infecção ocorre por meio da ingestão de larvas encistadas no tecido subcutâneo, na musculatura e vísceras de animais silvestres consumidos pelo homem de forma crua ou mal cozidos. A doença é rara, insidiosa, de caráter crônico, caracterizada pelo surgimento de lesões, principalmente na região do pescoço, mastoide, ouvido, rino e orofaringe. A gravidade, por vezes fatal, dependerá da localização do parasito.

Descrever um caso de otomastoidite por L. minor em criança, atendida no Hospital das Clínicas da Universidade Federal de Goiás.

Paciente 10 anos, sexo feminino, com queixa de otalgia intensa e otorreia purulenta à direita. À otoscopia, a orelha esquerda apresentava-se normal, enquanto na orelha direita havia edema retroauricular, pólipo no conduto auditivo externo e fístula com drenagem de secreção purulenta. A membrana timpânica estava íntegra. As etapas do atendimento foram descritas desde a consulta inicial até a recuperação da paciente.

O clínico deve estar alerta para importância em se considerar o diagnóstico diferencial de tal afecção diante de indivíduos residentes em zonas rurais.

otite média, zoonoses, parasitos.

The lagochilascariosis is an emerging zoonosis determined by the presence of helminth Lagochilascaris minor in human tissues. Infection occurs through ingestion of larvae encysted in the subcutaneous tissue, muscles and viscera of wild animals consumed by man so raw or undercooked. The disease is rare, insidious, chronic condition, characterized by the appearance of lesions, especially in the neck, mastoid, ear, nose and oropharynx. A serious, sometimes fatal, depend on the location of the parasite. To describe a case of otomastoiditis by L. minor in child, attended at the Hospital das Clinicas, Federal University of Goias.

Patient 10 years old female, complaining of otalgia and purulent otorrhea right. Otoscopy left ear was normal, while the right ear had retroauricular edema, polyps in the external ear canal and fistula with drainage of pus. The tympanic membrane was intact.The stages of treatment were described since the initial consultation to the recovery of the patient.

The clinician should be alert to the importance in considering the differential diagnosis of this disease on individuals residing in rural areas.

otitis media, zoonoses, parasites. 


\section{INTRODUÇÃO}

A lagochilascariose é uma a zoonose emergente determinada pela presença do helminto Lagochilascaris minor em tecidos humanos. Na literatura, encontra-se descritos cinco espécies do gênero, sendo L. minora única associada à infecção humana, a qual na fase adulta atinge aproximadamente 5 a $20 \mathrm{~mm}$ de cumprimento $(1,2,3)$.

Animais silvestres são considerados hospedeiros naturais sendo o homem, cães e gatos domésticos hospedeiros acidentais (2,4). CAmpos et al. (1992) descreveram o ciclo evolutivo experimental de L. minor. Estes autores confirmaram a hipótese formulada por SмiтH et al. (1983) de que a infecção humana é decorrente da ingestão de carne crua ou mal cozida contendo larvas encistadas em tecidos de roedores, hospedeiros intermediários (2). No estômago as larvas eclodem dos nódulos e migram por meio do esôfago para o trato digestivo superior (2).

A infecção por Lagochilascaris minoré rara, insidiosa, de caráter crônico, caracterizada pelo surgimento de abscessos supurados localizados na região do pescoço, mastoide, ouvido, rino e orofaringe. Ocasionalmente outras estruturas como, a rinofaringe, o cérebro, pulmões, seios paranasais, Trompa de Eustáquio, alvéolos dentários e o globo ocular, podem ser acometidos. A gravidade da doença depende da localização da lesão, da capacidade de reprodução do parasito, incursão do mesmo pelos tecidos e da resposta imune do hospedeiro $(1,2,3,6,7)$.

O diagnóstico da doença baseia-se na identificação de ovos, larvas e vermes adultos do parasito nas secreções presentes nas lesões. Os exames radiológicos são úteis para evidenciar a localização e extensão na das lesões, auxiliando na conduta clínica a ser seguida (3).

A terapêutica segue com o uso de Albendazol, Levamisol e a Dietilcarbamazina em doses elevadas. Entretanto, as recidivas são comuns mesmo após meses de cura. A remoção cirúrgica das larvas é um recurso utilizado para abreviar a cura $(2,7,10)$.

Mundialmente o Brasil ocupa o primeiro lugar em casos humanos de infecção por Lagochilascaris minor, a maioria procedente da região norte, em especial o Estado do Pará (7).

Neste artigo é proposto a apresentação de um caso, cuja relevância reside no fato deste se constituir em caso raro no ambulatório de otorrinolaringologia e em outras especialidades. Não foram encontrados registros de atendimento de tal doença nas últimas décadas, possivelmente pela raridade de sua ocorrência.

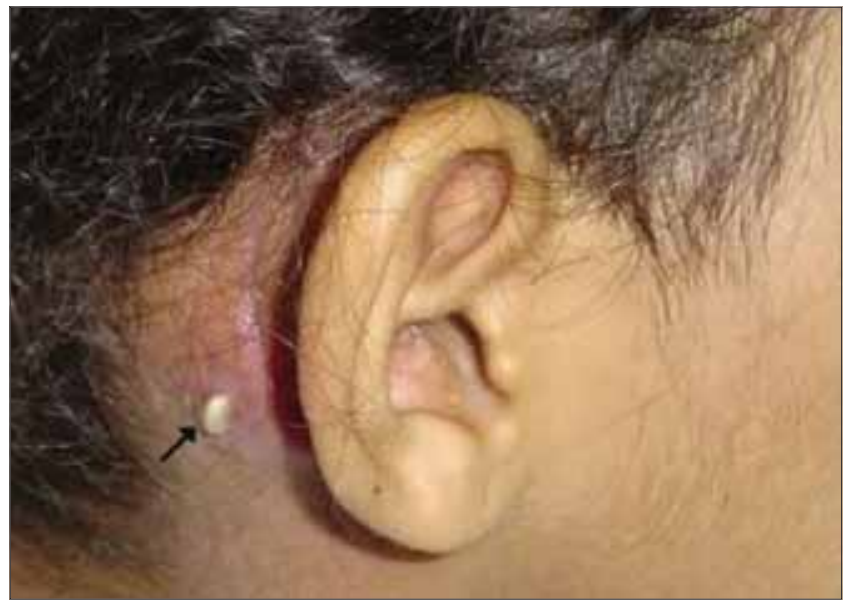

Figuira 1. Fístula retroauricular direita. Drenagem de secreção seropurulenta. Paciente SLQ residente de área rural do município de Canarana (MT). HC-UFG 2004.

No presente relato os autores descrevem um caso de otomastoidite por L. minor em criança, procedente do Estado do Mato Grosso, atendida no Hospital das Clínicas da Universidade Federal de Goiás, na cidade de Goiânia.

\section{Relato do Caso}

Paciente SLQ, 10 anos de idade, sexo feminino, estudante, natural de Barra do Garças (MT), procedente da zona rural do município de Canarana (MT), procurou o Pronto Socorro de Otorrinolaringologia do Hospital das Clínicas (HC) da Universidade Federal de Goiás (UFG) em abril de 2004, com o seguinte quadro clínico: otalgia intensa, otorreia purulenta, hiperemia e abaulamento retroauricular à direita.

A acompanhante afirmou que nos últimos dois meses a criança apresentou inchaço, dores com secreção purulenta na orelha direita, procurando uma unidade de saúde em sua cidade, sendo atendida por um médico otorrinolaringologista que realizou a drenagem do abscesso por incisão retroauricular sem melhora do quadro, passando a apresentar saída de secreção purulenta pelo orifício.

Na avaliação clínica otorrinolaringológica a orofaringoscopia e rinofaringoscopia anterior não apresentavam alterações. À otoscopia, a orelha esquerda apresentava-se normal, enquanto na orelha direita havia edema retroauricular, pólipo no conduto auditivo externo e fístula com drenagem de secreção purulenta. A membrana timpânica estava íntegra (Figura 1).

Diante do quadro clínico a paciente foi internada com diagnóstico de otomastoidite à direita sendo solicita- 


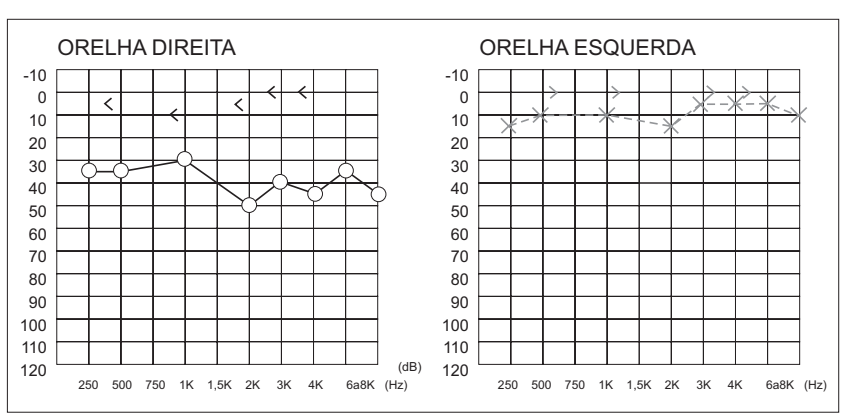

Figura 2. Audiometria tonal. Perda auditiva do tipo condutiva de grau leve à direita com limiares auditivos dentro dos padrões de normalidade à esquerda. HC-UFG 2004.

dos exames laboratoriais, cujos resultados mostraram-se normais na ocasião. Iniciou-se tratamento medicamentoso com antibioticoterapia endovenosa.

Os procedimentos de tomografia computadorizada de ossos temporais revelaram velamento de células mastóideas com material hiperdenso em orelha média, já a audiometria tonal detectou perda auditiva do tipo condutiva de grau leve à direita com limiares auditivos dentro dos padrões de normalidade à esquerda (Figura 2).

Três dias depois da consulta inicial, a paciente foi submetida à mastoidectomia direita. Feita a incisão, encontrou-se presença de tecido subcutâneo de aspecto esponjoso e secreção purulenta na região da mastoide e da orelha média. No pós-operatório precoce a infecção evoluiu com persistência da otorreia e da fístula retroauricular.

O exame histopatológico revelou tecido de granulação contendo de permeio acentuado infiltrado linfohistioplasmocitário e granuloma de tipo corpo estranho englobando fragmentos de parasito com camada quitinosa. Devido à fragmentação do parasito não foi possível identificá-lo com precisão, neste material.

No Laboratório de Biologia, Bioquímica e Imunologia de Helmintos (LBBIH) do Instituto de Patologia Tropical e Saúde Pública (IPTSP) da UFG, o diagnóstico definitivo foi firmado pelo exame parasitológico da secreção da fístula retroauricular com a identificação, ao exame direto a fresco, de ovos de $L$. minor e posteriormente, pelo exame coproparasitológico (Figura 3).

Após o diagnóstico foi administrada terapia especifica com levamisol (150 mg/dia) ivermectina ( $300 \mathrm{mg} / \mathrm{Kg} /$ semana) e posteriormente, albendazol ( $400 \mathrm{mg} / \mathrm{dia}$ ) com melhora acentuada do quadro otológico. A paciente recebeu alta com a mesma prescrição médica por mais 40 dias, com retorno posterior agendado ao ambulatório de otorrinolaringologia do hospital após 90 dias.

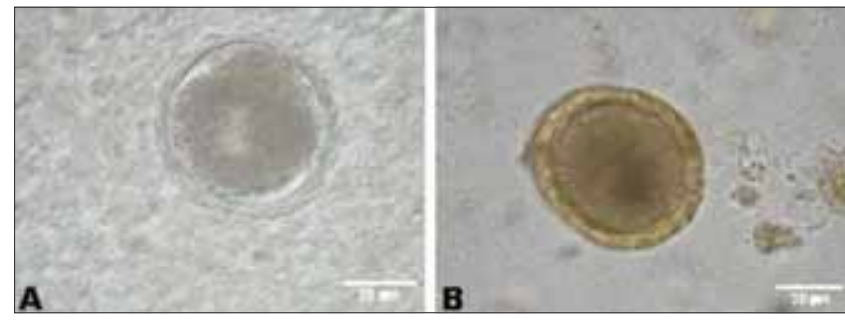

Figura 3. Ovos de Lagochilascaris minor em secreção seropurulenta de fístula retroauricular (A) e no exame coproparasitológico (B), da paciente SLQ residente de área rural do município de Canarana (MT). IP TSP-UFG 2004.

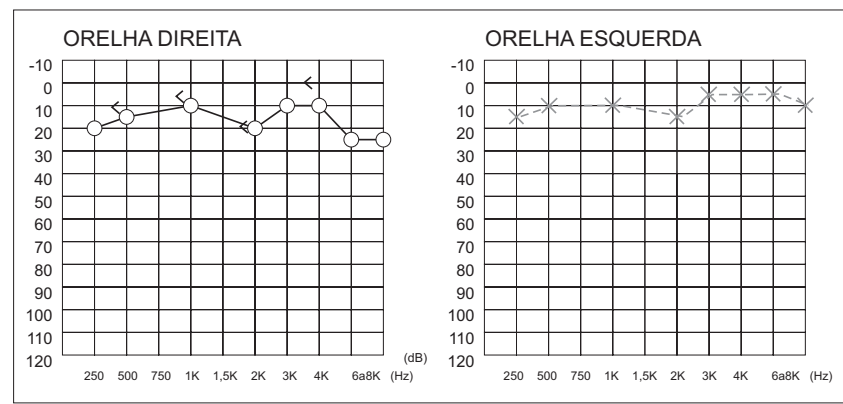

Figura 4. Audiometria tonal. Limiares auditivos dentro da normalidade em ambas as orelhas. HC-UFG 2005.

Três meses após a cirurgia a paciente retorna ao ambulatório, onde foi observada a formação de um discreto nódulo adjacente à lesão anterior, do qual houve eliminação espontânea de um pequeno verme vivo, segundo relato do pai da paciente. Após debridação cirúrgica o exame histopatológico revelou fragmentos de tecido conjuntivo com reação inflamatória crônica granulomatosa, contendo de permeio cortes de parasito sugestivo de Lagochilascaris. Foram prescritos dois ciclos de albendazol com intervalos de 15 dias intercalando com uma administração semanal de ivermectina. A paciente foi orientada a retornar ao ambulatório após seis meses para seguimento ao tratamento. Após este período, regressou sem sinais de otorreia ou infecção auricular direita, sendo realizado novo exame auditivo cujo resultado apresentava-se dentro da normalidade em ambas as orelhas (Figura 4).

A paciente recebeu alta, retornando a sua cidade de origem, sendo mantido o acompanhamento com as equipes de infectologia do HC e parasitologia do IPTSP-UFG.

\section{DISCUSSÃO}

O interesse na descrição deste caso é evidenciado na raridade de sua ocorrência, assim como o desenrolar e desfecho do mesmo. 
O diagnóstico da doença baseia-se na identificação de ovos, larvas e vermes adultos presentes nas lesões, onde a limpeza cirúrgica pode auxiliar na cura. No caso descrito, a paciente apresentou abscessos supurados na região mastóidea que, durante a remoção cirúrgica do mesmo, foi retirado material para biópsia, apresentando um resultado histopatológico sugestivo da infecção por $L$. minor confirmado, posteriormente, pelo exame parasitológico da secreção e das fezes do paciente $(3,7,9,10)$.

Geralmente as cirurgias otológicas requerem um cuidado em preservar a audição do indivíduo. Os exames laboratoriais da paciente apresentavam-se sem alterações não auxiliando no diagnóstico. Entretanto, exames como tomografia computadorizada de ossos temporais e audiometria auxiliaram no planejamento e conduta cirúrgica, como preconizam alguns estudos $(3,9)$.

A ingestão de carne de caça (paca e tatu) foi mencionada pela paciente encontrando-se na literatura que a doença é adquirida através da ingestão de larvas encistadas no tecido subcutâneo, musculatura e vísceras de animais silvestres $(1,3,4)$.

Considerando o processo recidivante da doença, utilizou-se a prescrição de albendazol e ivermectina por tempo prolongado com monitoramento das funções renal, hepática, hematopoiética e endócrino pancreática durante todo o tratamento. Medidas como a manutenção medicamentosa bem como o acompanhamento periódico ao ambulatório até a melhora clínica completa do quadro foram seguidas, como sugerem alguns autores $(3,7,8,10)$. Desconsiderar o processo recidivante e negligenciar o acompanhamento e manutenção do caso podem agravar o mesmo (9).

Durante todo o tratamento a paciente recebeu acompanhamento pelas equipes de otorrinolaringologia, infectologia e parasitologia da instituição.

\section{COMENTÁRIOS FinAIS}

O tratamento conjunto entre as equipes de otorrinolaringologia, infectologia e parasitologia bem como a participação e colaboração da paciente e de familiares frente à doença, comparecendo a todos os retornos, seguindo rigorosamente a prescrição médica, corroborou para o êxito no tratamento, considerando que os mesmos residem em outro Estado.

Ao clínico resta ficar atento para importância em se considerar o diagnóstico diferencial de tal afecção diante de indivíduos residentes em zonas rurais. Esta grave enfermidade parasitária pode afetar várias estruturas do organismo, comprometendo seriamente a saúde do paciente, com graves complicações que podem levar ao óbito.

\section{REFERÊNCIAS BIBLIOGRÁFICAS}

1. Barbosa AP, Campos DMB, Semerene AR, Teixeira AR, Santana JM. Lagochilascaris minor third-stage larvae secrete metalloproteases whit specificity for fibrinogen and native collagen. Microbes Infect. 2006, 8:2725-32.

2. Campos DMB, Freire Filha LG, Vieira MA, Paçô JM, Maia MA. Experimental life cycle of Lagochilascaris minor Leiper, 1909. Rev Inst Med Trop São Paulo. 1992, 34:277-87.

3. Palheta-Neto FX, Leão RNQ, Neto HF, Tomita S, Lima MAMT, Pezzin-Palheta AC. Contribuição ao estudo da lagoquilascaríase humana. Rev Bras Otorrinolaringol. 2002, 68:101-05.

4. Barbosa CAL, Barbosa AP, Campos DM.Gato doméstico (Felis catus domesticus) como possível reservatório de Lagochilascaris minor Leiper (1909). Rev Pat Trop. 2005, 34:211-53.

5. Smith JL, Bowman DD, Little MD. Life cycle and development of Lagochilascaris sprenti (Nematoda: ascarididae) from opossums (Marsupialia: didelphidae) in Louisiana. J Parasitol. 1983, 69:736-45.

6. Semerene AR, Lino Junior RS, Oliveira JA, Magalhães AV, Stefani MM, Barbosa AP, Campos DMB. Experimental lagochilascariosis: histopathological study of inflammatory response to larval migration in the murine model. Inst. Oswaldo Cruz. 2004, 99:393-8.

7. Vieira MA, Oliveira JA, Ferreira LS, Oliveira V, Barbosa CAL. Relato de caso de Lagochilascariose humana procedente do Estado do Pará, Brasil. Rev Soc Bras Med Trop. 2000, 33:87-90.

8. Rocha MPC, Fraiha NH, Barreto NACP. Infecção de ouvido médio e mastóide por Lagochilascaris minor Leiper, 1909 (Nematoda, Ascaridiae). Relato de um caso do Sul do Estado do Pará, Amazônia, Brasil. Hiléia Médica. 1984, 6:3-14.

9. Baracat DA, Freire EL, AquinoJL. Oto-mastoidite crônica por Lagochilascaris minorcom comprometimento da região temporo-parieto-occipital. Rev Univers Fed Mato Grosso. 1984, 2:9-14.

10. Monteiro AV, ZapotoskiSMK,Torres DMAGV, Berenchtein MA, Pinto PLS. Infecção por Lagochilascaris minor Leiper 1909, no Vale do Ribeira, estado de São Paulo, Brasil (Relato de Caso). Rev Inst Adolfo Lutz. 2004; 63:269-72. 